\title{
Numerical study on the applicability to manufacturing of contact-stress-optimised shaft-hub connections joined by lateral extrusion
}

\author{
Robert Jean-Phillipp Meissner ${ }^{1, *}$, Mathias Liewald ${ }^{1}$, Daniel Ulrich ${ }^{2}$, and Hansgeorg Binz ${ }^{2}$ \\ ${ }^{1}$ Institute for Metal Forming Technology, University of Stuttgart, Stuttgart, Germany \\ ${ }^{2}$ Institute for Engineering Design and Industrial Design, University of Stuttgart, Stuttgart, Germany
}

Received: 25 November 2019 / Accepted: 21 April 2020

\begin{abstract}
Shaft-hub connections, which are joined by plastic deformation of at least one component (e.g. joining by lateral extrusion), can meet today's contradictory requirements for high power densities with low manufacturing costs. As opposed to classical manufacturing methods, the tight manufacturing tolerances of shafts and hubs are not required here since the shaft is formed in the hub during the process to generate a combined frictional and positive-locking connection. However, plastic deformation generally results in an uneven distribution of contact stress, which causes negative effects such as increased hub stress and deformation, as well as the reduced transmission capacity of the connection. To overcome this effect, an iterative design approach for plastically stressed shaft-hub connections was developed in Ulrich et al. (2019)[1], in which the contact-stress distribution is influenced by contouring of the hub contact surface. Nonetheless, one major challenge in this process is the high sensitivity of the stress distribution to contour changes, particularly in the edge area of the connection, meaning that a dependency on tight manufacturing tolerances is present here, too. Therefore, an investigation is conducted to determine the extent to which deviations in the manufacturing process of the components, in the tool quality and during joining by lateral extrusion influence the resulting contact stress. In order to achieve this goal, numerical investigations are carried out, and the effects on the resulting contact-stress distribution are analysed. Finally, recommendations for manufacturing accuracy and process limits are derived in order to ensure manufacturability and enable the transfer of technology to industrial applications involving shaft-hub connections joined by lateral extrusion.
\end{abstract}

Keywords: Shaft-hub connections / lateral extrusion / cold forging / manufacturing / joining by forming

\section{Introduction}

Current research projects in the field of production engineering are focusing more than ever on the entire life cycle of a product with the aim of creating environmentally friendly solutions. As such, the objective is to minimise manufacturing steps and material loss while maintaining or improving the performance of components or assemblies. An important assembly for many industrial applications involving torque transmission is the shaft-hub connection. These assemblies are conventionally designed as frictionalor positive-locking connections (e.g. interference fits or spline connections). Both variants require precise material removal and tight manufacturing tolerances.

When joining shaft-hub connections using the lateral extrusion process, the final shape of the shaft is only achieved when it is pressed into the hub. Hence, by using circular or

\footnotetext{
* e-mail: robert.meissner@ifu.uni-stuttgart.de
}

non-circular contact surfaces in the hub, it is possible to create frictional- and/or positive-locking connections in a single stroke. While previous laboratory results for these connections showed promising static and dynamic torquetransmission capacities, the influence exerted on dynamic strength by contact-stress distribution was recognised. Industrial implementation of this manufacturing method is thus only feasible if the transmission capacity can be ensured while taking the expected component and manufacturing-process tolerances into consideration.

This study consequently focuses on the numerical analysis of various manufacturing and process tolerances' influence on the resulting contact-stress distribution. The goal is to derive process limits and recommendations for manufacturing tolerances for industrial application.

\section{State of the art}

The primary application of shaft-hub connections is the transmission of torsional forces. In addition, axial and/or 
radial forces can also be transmitted. The most relevant types of connection for this purpose are interference fits and positive-locking connections [2]. Positive-locking connections transfer their force through the surface pressure that is generated between the active surfaces and are capable of transmitting high and dynamic torques. However, the disadvantages are the rather high notch effect of the connections and the necessity of several manufacturing processes like machining, broaching and finish grinding to obtain the required precision for both parts.

In frictional connections, pressure between the contact surfaces is generated by an interference of two components. The more evenly the contact pressure is distributed over the contact surfaces, the better the transmission of force or torque and, in the case of round fits, also the centring of the parts. Due to their damping properties, interference fits are more favourable under dynamic loads than 'rigid' positivelocking connections. It must be ensured, that the operating force never exceeds the transmittable frictional force, whereby high safety factors must be taken into account since the coefficient of friction can only be calculated very imprecisely. This means that large preload forces are required; in other words, loading the component even when no external forces are applied [3].

In accordance with DIN 8593-5 [4], joining by forming involves local or complete forming of either the parts to be joined, or of auxiliary parts. Recent research activities investigated several different techniques. Marré investigated joining involving the forming of thin-walled tubes [5] and principally verified the feasibility of hybrid joining, combining the forming processes of rolling, die-less hydroforming and electromagnetic compression with an adhesive, although all processes are limited to the use of hollow, thin-walled tubes. With regard to shaft-hub connections, knurled joints were investigated by Kitamura and Hirota [6,7], whereby no preparation of the two joining partners is required. In addition to the frictional connection due to the elastic tension of the components, a form fit was achieved by pressing a profiled rod into a ductile hub. The challenge for joining by forming with knurled hubs or knurled shafts is to ensure that no machining of the nonknurled joining partner occurs during the joining process. Furthermore, the hub needs to be relatively soft in order to be formed by the knurled shaft. Suchý et al. investigated the opposite combination - a hardened hub and soft shaft - for small length/diameter ratios. The knurled profiles used yielded high notch effects during fatigue tests [8].

The essential characteristic of lateral extrusion is the generation of a material flow perpendicular to the punch movement. In contrast to upsetting, the shaping, lateral die opening remains constant. In general, a cylindrical blank is used, which is laterally extruded under the effect of one or two punches arranged in the axial direction [9]. Alves et al. used a lateral extrusion process, namely boss forming, to manufacture either flanges on rods or tubes and, secondly, to join rods and thin-walled tubes to thin sheets [10].

Investigations by Dörr and Funk $[11,12]$ focused on shaft-hub connections joined by lateral extrusion and demonstrated significantly higher static torque transmission compared to thermally joined interference fits. The cold forging process for establishing the shaft-hub connection is performed in one stroke through the lateral extrusion of a cylindrical shaft positioned in a hardened hub. Placing the hub between radially preloaded die segments prevents impermissible tangential stress in the hub during and after forming. Due to the process of forming one component in its counterpart, a clearance-free connection is produced, which potentially minimises slip in the joint. For the same reason, the production of a combined positive- and frictional-locking connection is advantageous with a view to the transmission of high torsional loads under static and dynamic conditions.

Slip between components - and the associated fretting effects - have been identified as the main cause of failure in dynamically stressed spline connections [13]. Shaft-hub connections manufactured by means of lateral extrusion with non-circular joining surfaces showed the same behaviour in experiments under dynamic torque [12]. Here, the main cause for slip has been identified as nonuniform contact-stress distribution in the interstice, which is a direct result of the forming process. During lateral extrusion, the material automatically creates a barrelling of the cylindrical outer contour [14]. Consequently, when forming the shaft in the hub through cold forming, inhomogeneous stress distribution and incomplete formfilling occur, as shown in Figure 1 for an axisymmetric example [1]. In order to minimise fretting and increase the connection's dynamic strength, complete and uniform contact must be ensured. Recent developments have therefore focused on a design method for homogenising the contact stress in the joint based on elastic-plastic FE simulations. The procedure described in [1] is presented below for the sake of clarity.

\section{Procedure for contour design}

To achieve the objective of homogeneous contact-stress distribution, the inner contour of the hub is modified by radial displacement based on the simulation results and thus adapted to the convex shape of the formed shaft material. Unlike the use of a contoured shaft in combination with a cylindrical hub surface, a concave-shaped hub provides additional axial locking of the components in the joined state. Due to the complex interdependencies between the shape of the inner hub contour, the forming behaviour of the shaft material and the resulting contact stress, form finding cannot be performed in one step, and several iterations for the contact stress are required to approach the target distribution. For this purpose, an iterative procedure is used, which is automated by a Python script and depicted in Figure 2.

The starting point for the calculation is an initial FE simulation based on the unmodified geometric models of the joining partners, the material models used, the boundary conditions, the mesh parameters and the punch stroke. Further input parameters are the defined target contact-stress distribution and optimisation settings. The following repetitive steps include updating (1) and running the simulation (2) for the elastic-plastic FE model, analysis of the contact-stress results (3) and subsequent 


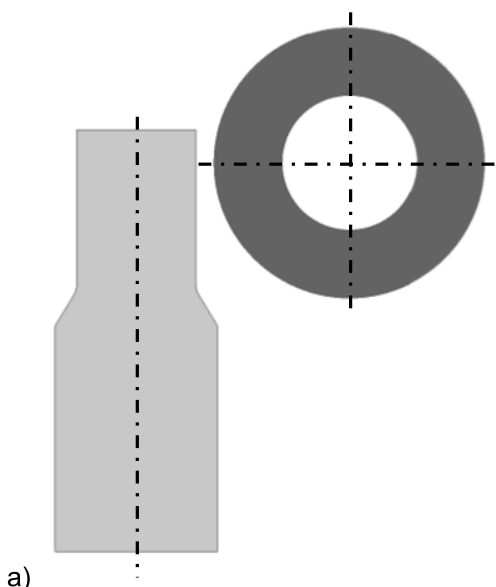

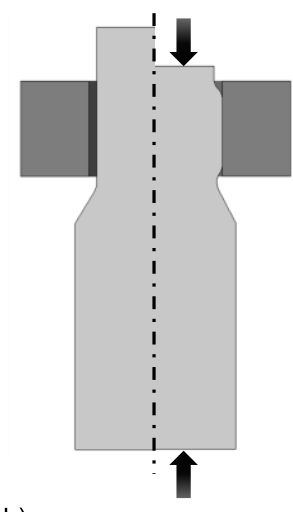

b)

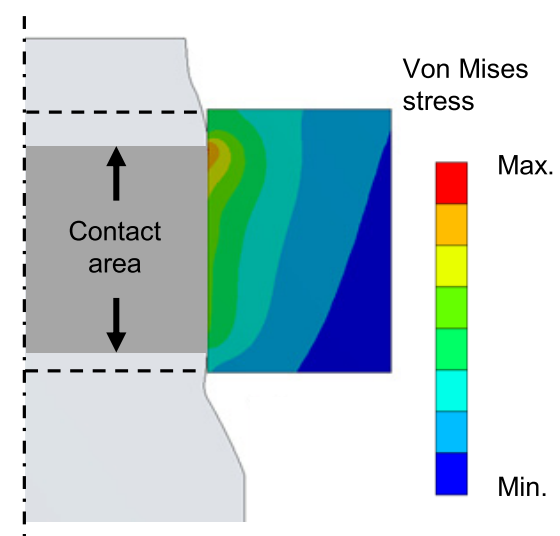

c)

Fig. 1. (a) Shaft and hub; (b) assembly before and after joining by forming; (c) non-uniform von Mises stress distribution in the hub and incomplete form filling after joining by forming [1].
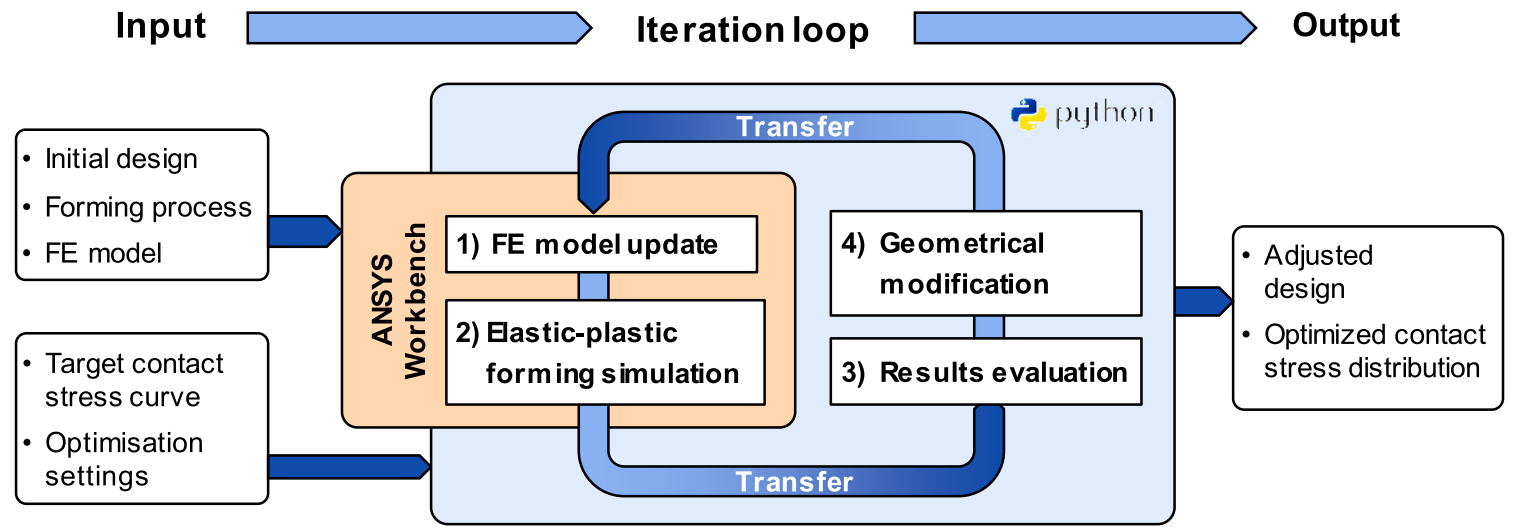

Fig. 2. Iterative design adaptation for plastically stressed shaft-hub connections, yielding optimised contact-stress distribution [1].

modification of the inner hub contour (4). In this manner, the concave inner contour of the hub is geared towards the desired design.

After each iteration, the root-mean-square error (RMSE) of the contact-stress results with respect to the target stress is determined and used as an objective function for selecting the most promising design solution.

So far, this investigation has been carried out in Ansys Workbench to demonstrate feasibility. In the scope of this work, the more specialised forming-simulation tool Deform2 ${ }^{\mathrm{TM}}$ was used.

\section{Numerical model for investigation}

In order to simulate the manufacturing of an axisymmetric shaft-hub connection by means of lateral extrusion for the present study, a numerical model was set up in Deform $2 \mathrm{D}^{\mathrm{TM}}$ that contained the components and process definitions. The forming process is modelled as a four-stage simulation (see Fig. 3). Firstly, the hub is preloaded radially to avoid impermissible tensile stresses in the hub during and after joining. For this purpose, the preloading segments are moved vertically by $0.1 \mathrm{~mm}$ creating a radial movement through a taper angle of $9^{\circ}$. Following this, the forming step is carried out by moving the punch axially by $7.2 \mathrm{~mm}$. Subsequently, the punch and the preloading segments are removed from the model to release the joined connection. In the fourth step, a numerical equilibrium is calculated for the entire assembly.

To save computation time, the lateral extrusion process is set up as a $2 \mathrm{D}$ model. The shaft was meshed with 2950 elements and the hub with 1600 elements, using mesh morphing to account for the modification of the inner hub contour. Mesh windows were used in order to achieve an element edge length of $0.2 \mathrm{~mm}$ in the contact area. The mesh used reflects a good compromise between quality of the contact-stress results and calculation time. A single simulation has a run time of about $30 \mathrm{~min}$ on a current workstation. Considering twice the number of elements in the contact area, an increase of run time by a factor of six was determined without a significant change of the contact stress. On the contrary, halving the number of elements showed a decrease of run time by a factor of two, although also a significant difference in results. 

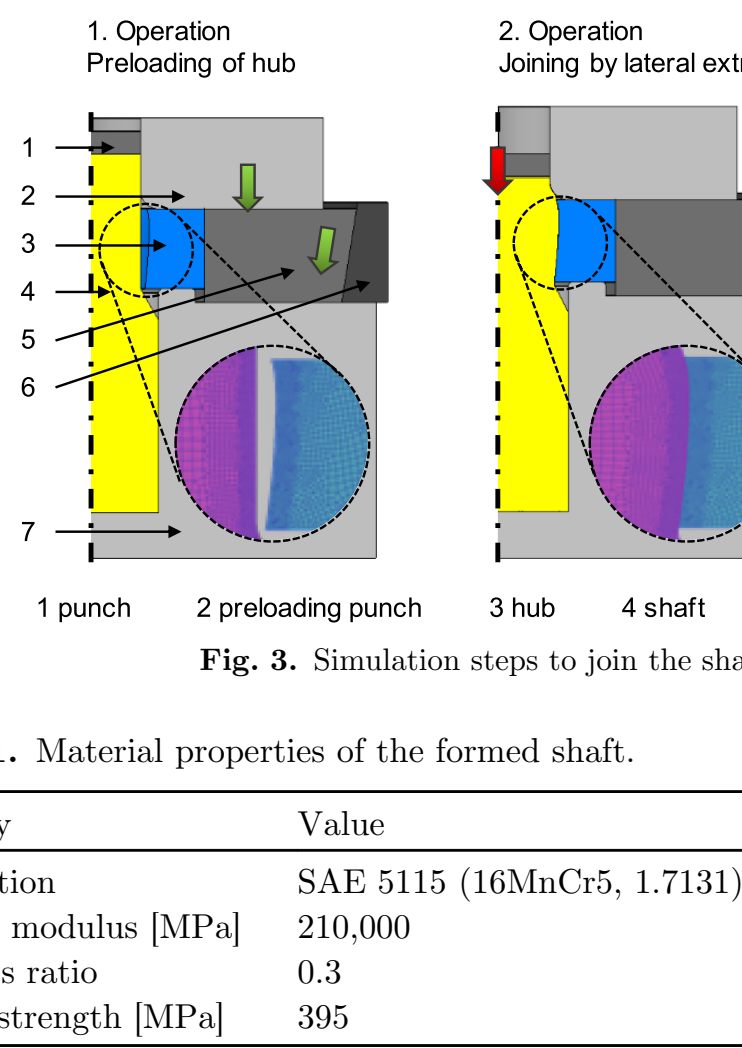

Table 1. Material properties of the formed shaft.

\begin{tabular}{ll}
\hline Property & Value \\
\hline Designation & SAE 5115 (16MnCr5, 1.7131) \\
Young's modulus [MPa] & 210,000 \\
Poisson's ratio & 0.3 \\
Tensile strength [MPa] & 395 \\
\hline
\end{tabular}

The shaft was modelled with elastic-plastic material behaviour, while the hub, the preloading segment, preloading punch and shaft die were ideal elastic. The punch and the preloading die were modelled rigidly. Friction during the forming process - and between the contacting tooling part - was modelled using Coulomb's model and a coefficient of friction of $\mu=0.1$. The material data for the shaft are presented in Table 1. The investigation was performed using the flow curves of case-hardening steel SAE 5115 obtained at the strain rates $11 / \mathrm{s}$ and $101 / \mathrm{s}$ in a temperature range from $20^{\circ} \mathrm{C}$ to $400^{\circ} \mathrm{C}$. The flow curves gained through the standardised German Cold Forging Group detection procedure were extrapolated by employing the Ludwik approach and are shown in Figure 4.

Prior to the tolerance investigation of shaft-hub connections manufactured by lateral extrusion, a concave inner hub contour was identified using the iterative-design method according to [1] in order to obtain a uniform contact-stress distribution of $250 \mathrm{MPa}$ in the interstice. In Figure $5 \mathrm{a}$, the radial-stress distribution in the hub is displayed for the initial straight design and for the optimised inner hub contour. It can be clearly seen that high radial stresses of nearly $550 \mathrm{MPa}$ occur in the hub at the lower and upper edges.

In the middle section of the hub, the stresses are merely half as high. On the contrary, the optimised inner hub contour only creates minor deviations along the axial length of the hub. The comparison of radial displacements between the initial and optimised inner hub contour reveals that an optimised contour results in a lower and more uniform displacement after the joining process, which

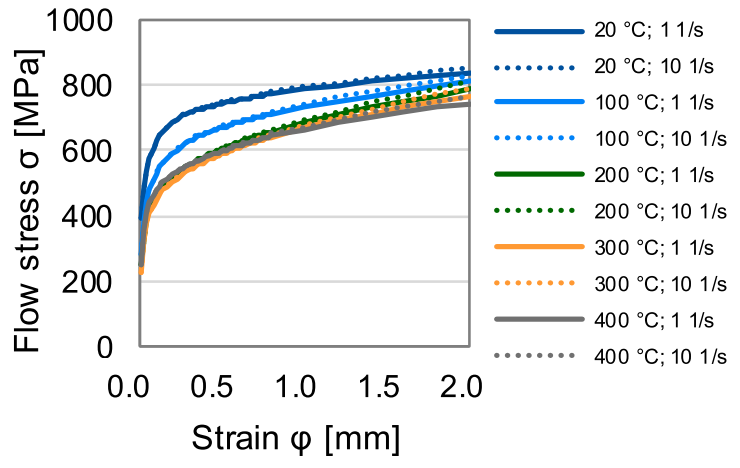

Fig. 4. Flow curves of case-hardening steel SAE 5115 at different strain rates and temperatures (extrapolated through Ludwik approach).

a)
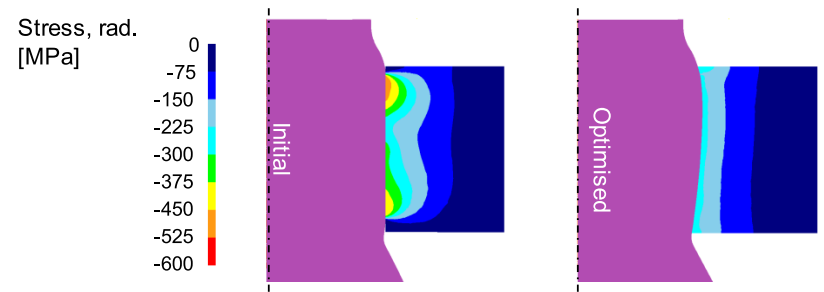

b)

$\begin{array}{cc}\text { Displacement, rad. } \\ \text { [mm] } & 0.0440 \\ & 0.0410 \\ & 0.0380 \\ 0.0250 \\ 0.0320 \\ 0.0290 \\ 0.0260 \\ 0.0230 \\ 0.0200\end{array}$
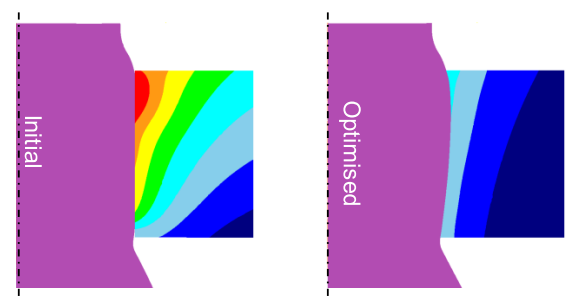

Fig. 5. (a) Radial stress and (b) radial displacement of the initial and optimised inner hub contour.

reduces the need for subsequent manufacturing processes like grinding.

Figure 6 presents a comparison of contact-stress distributions of a hub providing a straight inner contour (original) and an optimised inner contour. The uniform 


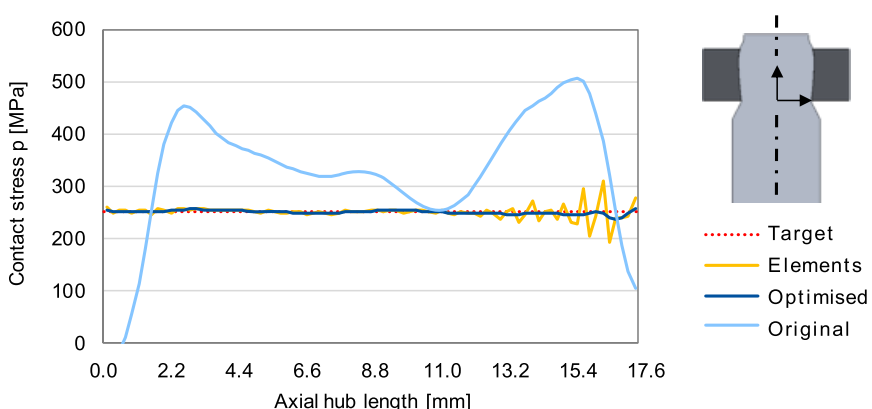

Fig. 6. Distribution of contact stress of initial straight hub and optimised concave hub contour.

target-stress distribution at a level of $250 \mathrm{MPa}, p_{\text {target }}$, is represented by a dotted line. In order to characterise the calculated contact-stress distributions, a third-order Butterworth filter was used on the raw element results to filter the strong numerical deviations of the FEA contact-stress values. To illustrate the filter effect, the contact-stress distribution corresponding to the optimised contour is shown twice: as raw element result data $p_{\text {elements }}$ retrieved from the simulation and as a filtered distribution poptimised.

Three characteristic values were subsequently evaluated to compare the contact-stress distributions: mean contact stress, root-mean-square error (RMSE) with respect to the target value and difference between the minimum and maximum contact stress value (spread). While the mean contact stress and RMSE value may be considered general characteristics of the connection, the evaluated min-max spread mainly serves as an indicator for the edge areas, which influence the performance of plastically stressed shaft-hub connections under dynamic load.

The straight hub contour results in a highly nonuniform contact-stress distribution $p_{\text {original }}$ with a mean contact-stress value of $326 \mathrm{MPa}$ and two significant peaks of $453 \mathrm{MPa}$ and $507 \mathrm{MPa}$. Furthermore, the contact stress decreases to $0 \mathrm{MPa}$ at the lower hub edge, which causes a wide spread between minimum and maximum contactstress values. At the same time, the results are much more uniform with the optimised inner hub contour at a mean contact stress of $250 \mathrm{MPa}$ and a spread of $23 \mathrm{MPa}$ between the minimum and maximum contact-stress level.

\section{Numerical study on component and process tolerances}

Former investigations focused on the feasibility of the manufacturing process and the general performance of the joined components. In order to enable a transfer to industrial applications, manufacturing tolerances during workpiece preparation need to be considered. The forming process is subject to general manufacturing tolerances, such as machine and tool tolerances or part tolerances due to the prior manufacturing process. ISO 286-1 classifies general tolerance classes to a certain measure like the diameter or length [15]. In principle, the achievable accuracy depends on the manufacturing process. Dimensional accuracy up to tolerance class IT7 can be achieved
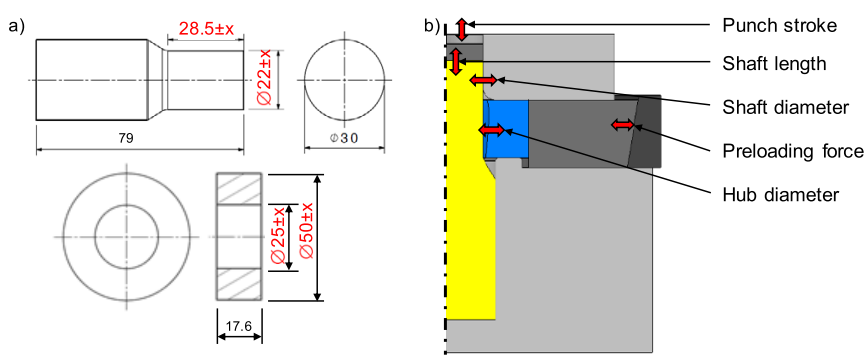

Fig. 7. (a) Specimen dimensions and dimensions to be investigated (marked in red); (b) illustration of machine and tool tolerances in numerical-simulation setup.

Table 2. Investigated machine parameters and geometric component tolerance according to IT7 and IT10 of ISO 286-1 [15].

\begin{tabular}{llll}
\hline Geometric parameters & IT7 & IT10 \\
\hline Shaft & Diameter & $22 \pm 0.0105 \mathrm{~mm}$ & $22 \pm 0.042 \mathrm{~mm}$ \\
& Height & $79 \pm 0.015 \mathrm{~mm}$ & $79 \pm 0.060 \mathrm{~mm}$ \\
Hub & Inner diameter & $25^{*} \pm 0.0105 \mathrm{~mm}$ & $25^{*} \pm 0.042 \mathrm{~mm}$ \\
\multicolumn{4}{c}{ Machine and tool parameters } \\
Press & Punch stroke & $\pm 0.1 \mathrm{~mm}$ \\
Tool & Hub preloading & $\pm 25 \%$ & \\
\hline
\end{tabular}

with cold forging. With semi-hot forming, only production tolerance IT10 is achievable without special manufacturing processes [16]. For this study, manufacturing tolerances shown in Figure 7 were considered. The dimensions marked in red, which represent the primary parameters for affecting contact stress, were varied. Alongside component accuracy, machine accuracy plays an important role in high-precision manufacturing. Therefore, machine tolerances concerning punch-stroke deviations and hub preloading were also examined.

The investigations presented in this section focused on the alteration of one single parameter at a time; therefore, tolerance interactions were not yet considered. A worstcase study including tolerance interactions was conducted separately and is presented in the next section of this paper.

The tolerance values are summarised in Table 2. For the variable diameter of the inner hub contour $(*)$, a mean value of $25 \mathrm{~mm}$ was considered with regard to the tolerance class.

\subsection{Influence of machine and tool accuracy with respect to contact-stress distribution}

Figure 8 shows the influence of machine and tool tolerances on the contact-stress distribution of an optimised inner hub contour. A longer or shorter stroke, respectively, results in a high deviation of contact stress at the lower and upper hub edge. While a longer stroke causes a level of contact stress twice as high as the target, a shorter stroke results in a drop to zero at both hub edges. 


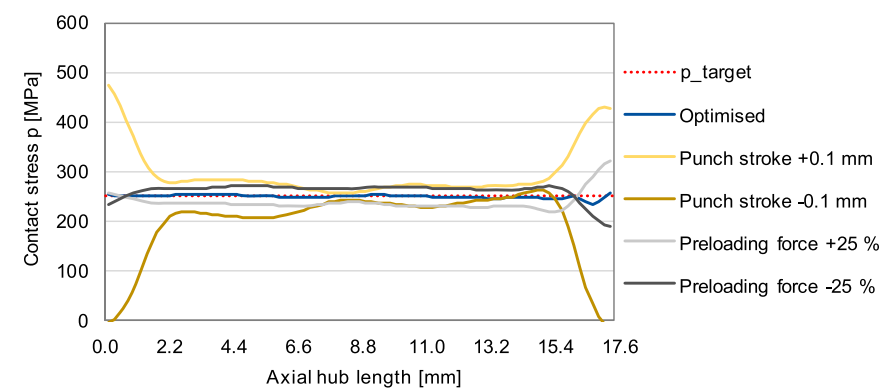

Fig. 8. Contact-stress distribution with respect to machine and tool tolerances.

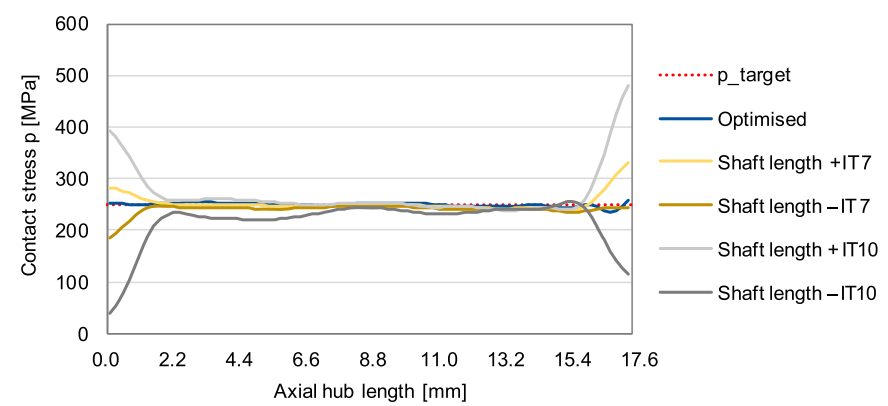

Fig. 9. Contact-stress distribution with respect to shaft-length tolerances.

Contrary to punch-stroke tolerances, neither lower nor higher preload forces cause a significant difference in the initial contact-stress distribution. Both alterations show the highest deviations at the upper hub area. While preloading the hub, a radial elastic displacement of the inner contour occurs. The higher the displacement, the higher the elastic spring-back after the load is released. As such, the cavity to be filled during the process of joining by forming changes and a difference in the mean contact stress of up to $5 \%$ in comparison to the optimised contour was determined.

\subsection{Influence of shaft length with respect to contact-stress distribution}

Differences in the shaft length are likely to occur when preparing raw parts through sawing or shearing. Figure 9 shows the contact-stress distribution when applying an optimised hub contour and ideal shaft length in comparison to different shaft lengths to be joined. A geometric tolerance of IT7 results in an overall contact-stress difference of $-4 \%$ or $+1 \%$ and RMSE values of $40.7 \mathrm{MPa}$ or $38.9 \mathrm{MPa}$, respectively. When providing a tolerance class of IT10, the mean contact stress ranges from $-13 \%$ to $+8 \%$, and the RMSE is six times higher in comparison to the optimised hub, with the spread between the minimum and maximum contact stress increasing to $241 \mathrm{MPa}$

\subsection{Influence of shaft and hub diameter with respect to contact-stress distribution}

A manufacturing tolerance for the shaft diameter has a more significant influence on the contact-stress

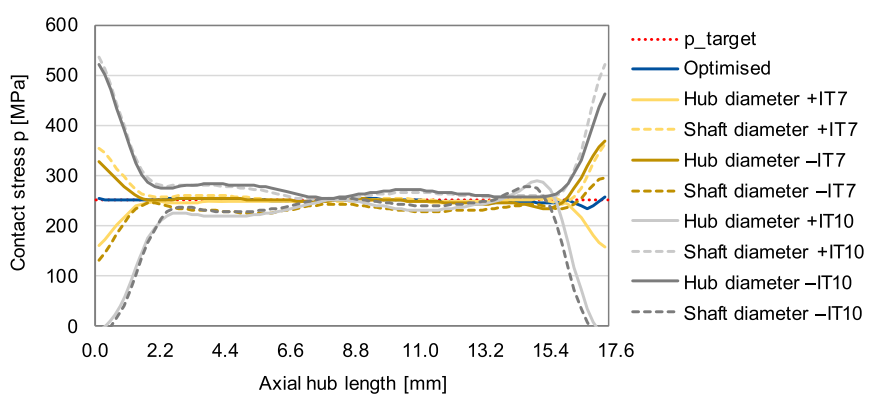

Fig. 10. Contact-stress distribution with respect to hub- and shaft-diameter tolerances.

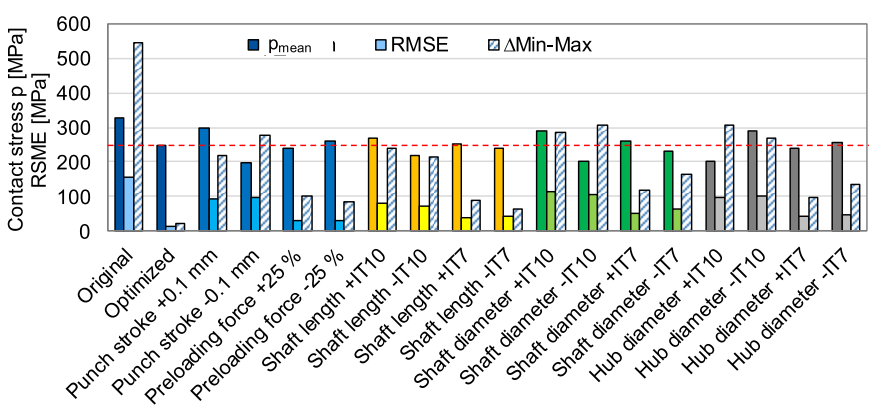

Fig. 11. Comparison of mean contact stress and RSME for geometric and machine-related tolerances.

distribution than the shaft length. Figure 10 presents the contact-stress distribution with respect to manufacturing tolerances of the shaft and inner hub diameter.

While IT7 mainly causes deviations in the areas of the upper and lower edges, IT10 also results in noticeable deviations of contact stress along the complete inner hub contour. The investigation reveals very similar results when the diameters of both components are varied, since both affect the initial distance between the shaft and hub to the same extent. From this, a strong dependency between the component dimensions can be identified. A wider shaft and a narrower inner hub diameter result in high contactstress levels in both edge areas. By contrast, smaller shaft diameters and larger inner hub diameters result in an equivalent decrease in the contact-stress levels in the same areas. The unexpected contact stress at the upper hub edge (axial length $17.6 \mathrm{~mm}$ ) for a thinner shaft diameter of tolerance class IT7 was identified as a numerical outliers.

\subsection{Comparison of mean contact stress and RMSE values}

In order to compare the various tolerances and develop a strategy to determine a suitable tolerance system for manufacturing, Figure 11 presents the mean contact stress, RMSE value and min-max spread for each investigated tolerance. With regard to forming process and tool tolerances, varying preloading-force levels only resulted in minor changes in the mean contact stress, RMSE and min-max spread, while an alteration of the punch stroke by $0.1 \mathrm{~mm}$ showed a strong influence on these values. Considering manufacturing tolerances for the components, on the one hand, tolerance class IT7 only caused minor 


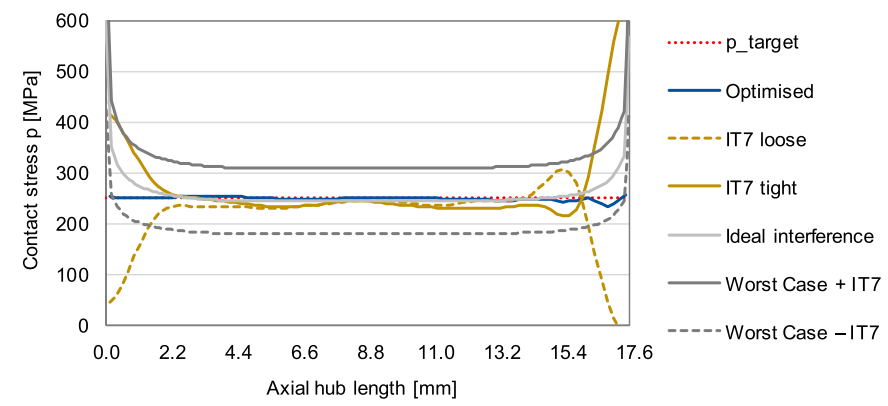

Fig. 12. Comparison of IT7 worst-case contact-stress distributions to interference-fit connection.

deviations in comparison to the optimised parameter set. On the other hand, the tolerance class IT10 resulted in deviations of up to $20 \%$ in the mean contact stress. Overall, the alteration of the shaft diameter and the hub diameter exhibited the strongest influence on the mean contact stress and RMSE values, while the influence of the shaft length was less significant.

Across all analysed parameter variations, a strong correlation can be discerned between the three evaluated characteristics. Additionally, all deviations from the optimised contact-stress distribution remain significantly smaller than the original straight contour, which indicates reasonable applicability of the method, even when loose tolerances are applied.

For two pairs of parameters (namely punch stroke and shaft length, and shaft diameter and inner hub diameter), almost identical effects on the contact-stress distribution can be identified. In both cases, the mutual dependency needs to be considered when determining manufacturing tolerances.

\section{Applicability to manufacturing}

In the first study in Section 5, only one parameter at a time was examined. In order to understand the interactions between tolerances when manufacturing individual parts, a worst-case study was conducted for tolerance class IT7. The machine tolerances were not considered as these can be precisely adjusted during the manufacturing process, especially for cold forging. Consequently, the combinations of a short and narrow shaft with a wide hub (IT7 loose) and a long and wide shaft with a narrow hub (IT7 tight) were investigated. Figure 12 shows the contact stress for 'IT7 loose' and 'IT7 tight' in comparison to the ideal combination. Overall, the mean contact stress remains at a similar level. In the case of 'IT7 loose', a mean contact stress of $217 \mathrm{MPa}(-13 \%)$ was determined, while the mean contact stress of 'IT7 tight' was $270 \mathrm{MPa}(+8 \%)$. In contrast to ideal component dimensions, however, high deviations in terms of contact stress appear at the hub edges. While the difference between minimum and maximum contact stress is only $23 \mathrm{MPa}$ in optimum conditions, a delta of $326 \mathrm{MPa}$ was determined for 'IT7 loose', with $430 \mathrm{MPa}$ for 'IT7 tight'.

Since the deviations seem to be rather high, further investigation regarding an equivalent interference-fit connection was conducted to compare the respective worst-case results. Therefore, the contact stress was simulated for the analytically calculated ideal interference value, as well as for minimum and maximum values using tolerance class IT7. The resulting contact-stress distributions are also shown in Figure 12. While the mean contact stress of an ideal interference fit was calculated as $262 \mathrm{MPa}$ $(+5 \%)$, it already shows a high delta of $366 \mathrm{MPa}$ between the minimum and maximum contact stress resulting from high peaks in the lower and upper hub area. The mean contact stress for minimum and maximum interference are clearly lower $(193 \mathrm{MPa},-23 \%)$ and higher $(332 \mathrm{MPa}$, $+33 \%$ ), respectively, in comparison to the target contact stress of $250 \mathrm{MPa}$. However, the difference between the minimum and maximum contact stress is not significantly affected by manufacturing tolerances and remains close to the level of an ideal interference fit.

Taking tolerance class IT7 into consideration for manufacturing shaft-hub connections, it can be stated that joining by means of lateral extrusion yields a significant improvement in the targeted adjustment of contact stress. The mean contact stress of shaft-hub connections manufactured by lateral extrusion remains closer to the targeted level, while the contact-stress deviations close to the hub edges are comparable to equivalent interference-fit connections.

\section{Summary and outlook}

This paper presented the influence of manufacturing tolerances on the contact stress in the interstice when joining shaft-hub connections by means of lateral extrusion. For use as reference, a suitable connection exhibiting a uniform contact-stress distribution at a level of $250 \mathrm{MPa}$ was designed using a new FEA-based design method, which was also briefly presented. The manufacturing process for joining by forming was modelled using DEFORM $2 \mathrm{D}^{\mathrm{TM}}$ numerical forming software, including radial preloading of the hub and considering elastic spring-back after the load is released. The influence of manufacturing tolerances on the contact-stress deviation was investigated numerically in two studies by running FEA simulations with geometrically modified models. The first study focused on the influence of single parameter variations and was followed by a worst-case study of manufacturing tolerances regarding the components to be joined.

The relevant process parameters for the first study were identified as the punch stroke and radial preloading force, whereas the significant geometric parameters of the components were determined to be the shaft length and diameter, as well as the inner hub diameter. While a preloading difference of $+/-25 \%$ did not reveal noteworthy contact-stress deviations, a shorter or longer punch stroke of $0.1 \mathrm{~mm}$ significantly affects both the mean contact stress and the contact-stress distribution. Considering geometric modifications, an alteration of the distance between the shaft and the inner hub contour causes the highest deviations in contact stress. While tolerances of IT7 might yield suitable results for subsequent use, IT10 reveals noticeable deviations to the targeted mean contact 
stress and an overall non-uniform contact-stress distribution with higher peaks near the hub edges. Nonetheless, all deviations from the reference contact-stress distribution remain relatively small compared to the original hub design, which indicates reasonable applicability of the method, even when loose tolerances are applied.

The worst-case study was conducted by modifying the geometric parameters of shaft and hub simultaneously in accordance with tolerance class IT7. The contact-stress results were compared to a conventional interference-fit connection that provided the same tolerance class. In summary, joining by lateral extrusion provides a significant improvement in the targeted adjustment of the contact stress. The mean contact stress of shaft-hub connections manufactured by lateral extrusion remains closer to the targeted level, while the difference between the minimum and maximum contact stress is equivalent to a conventional interference fit.

The following conclusions and recommendations can be drawn from the studies. A tolerance class of IT7 is recommended for the joined components if contact stress at the hub edges is of high importance. However, looser tolerances can still provide a reasonably small deviation from the mean contact stress and can therefore be used if the contact-stress level at the hub edges is negligible. Precise adjustment of the process parameters prior to manufacturing is advised, especially to cancel out the significant influence of punch-stroke variations. Certain pairs of parameters have been identified that can either increase or mutually compensate for their negative effect on the contact-stress distribution. For industrial applications, the influence of component tolerances could therefore be minimised by measuring the dimensions of all components and pairing suitable joining partners prior to the joining process.

The research culminating in these results has received funding from the Deutsche Forschungsgemeinschaft (DFG, German Research Foundation); project no.: 397117393.

\section{References}

1. D. Ulrich, H. Binz, R. Meissner, M. Liewald, Iterative design method for plastically stressed shaft - hub connections with optimized contact stress, in NAFEMS World Congress (2019) 322-339
2. F.G. Kollmann, Welle-Nabe-Verbindungen - Gestaltung, Auslegung, Auswahl (Springer-Verlag, Berlin, Heidelberg, 1984)

3. H. Haberhauer, Maschinenelemente-Gestaltung, Berechnung, Anwendung, 18. vol. 136, no. 1. Esslingen (Springer Berlin Heidelberg, 2017)

4. DIN, 'DIN 8593-5 Manufacturing processes joining - Part 5: Joining by forming processing - Classification, subdivision, terms and definitions' no. September. Deutsches Institut für Normung e.V., Berlin, p. 14, 2003.

5. M. Marré, A. Brosius, A.E. Tekkaya, New aspects of joining by compression and expansion of tubular workpieces, Int. J. Mater. Form. 1 (2008) 1295-1298

6. K. Kitamura, K. Hirota, Y. Ukai, K. Matsunaga, K. Osakada, Cold joining of rotor shaft with flange by using plastic deformation, CIRP Ann. - Manuf. Technol. 61 (2012) 275-278

7. K. Hirota, K. Kitamura, Y. Ukai, K. Matsunaga, Mechanical joining of shaft and holed disc in rotational and axial directions, Proc. Eng. 207 (2017) 980-985

8. L. Suchý, E. Leidich, A. Hasse, T. Gerstmann, B. Awiszus, Fatigue strength of inner knurled interference fit joined by forming and cutting methods, Frat. ed Integrita Strutt. 13 (2019) 429-434

9. K. Lange, M. Kammerer, K. Pöhlandt, J. Schöck, 'Fließpressen - Wirtschaftliche Fertigung metallischer Präzisionswerkstücke' (Springer-Verlag, Berlin Heidelberg, Stuttgart, 2008)

10. R.M. Afonso, L.M. Alves, P.A.F. Martins, Joining by boss forming of rods and tubes to sheets, J. Adv. Join. Process. 1 (2020) 100001

11. F. Dörr, Beitrag zum Umformfügeprozess einer Welle-NabeVerbindung durch Querfließppressen, Dissertation, University of Stuttgart, Stuttgart, 2016

12. M. Funk, Tragfähigkeit von mittels Quer-Fließpressen hergestellten Welle-Nabe- Verbindungen bei Torsionsbeanspruchung, Dissertation, Universität Stuttgart, 2017

13. J. Vidner, Methode zur Bewertung der Ermüdungsfestigkeit von reibdauerbeanspruchten Systemen, Dissertation, Technical University of Chemnitz, 2016

14. W. Schätzle, Querfliesspressen eines Flansches oder Bundes an zylindrischen Vollkörpern aus Stahl, Dissertation, University of Stuttgart, Stuttgart, 1987

15. DIN, 'DIN EN ISO 286-1 Geometrical product specifications (GPS) - ISO code system for tolerances on linear sizes - Part 1: Basis of tolerances, deviations and fits' Deutsches Institut für Normung e.V., Berlin, 2019.

16. E. Doege, B.-A. Behrens, Handbuch Umformtechnik Grundlagen, Technologien, Maschinen, 2 (Springer-Verlag, Berlin Heidelberg, Heidelberg, 2010)

Cite this article as: Robert Jean-Phillipp Meissner, Mathias Liewald, Daniel Ulrich, Hansgeorg Binz, Numerical study on the applicability to manufacturing of contact-stress-optimised shaft-hub connections joined by lateral extrusion, Manufacturing Rev. $7,21(2020)$ 